\title{
Estimated glomerular filtration rate at reinitiation of dialysis and mortality in failed kidney transplant recipients
}

\author{
Miklos Z. Molnar ${ }^{1,2}$, Elani Streja ${ }^{1}$, Csaba P. Kovesdy ${ }^{3,4}$, Junichi Hoshino ${ }^{1,5}$, Parta Hatamizadeh ${ }^{1}$, \\ Richard J. Glassock ${ }^{6}$, Akinlolu O. Ojo ${ }^{7}$ and Kamyar Kalantar-Zadeh ${ }^{1,5,6}$
}

\begin{abstract}
${ }^{1}$ Harold Simmons Center for Chronic Disease Research \& Epidemiology, Los Angeles Biomedical Research Institute, HarborUCLA Medical Center, Torrance, CA, USA, ${ }^{2}$ Institute of Pathophysiology, Semmelweis University, Budapest, Hungary, ${ }^{3}$ Division of Nephrology, University of Virginia, Charlottesville, VA, USA, ${ }^{4}$ Division of Nephrology, Salem VA Medical Center, Salem, VA, USA, ${ }^{5}$ UCLA School of Public Health, Los Angeles, CA, USA, ${ }^{6}$ David Geffen School of Medicine at UCLA, Los Angeles, CA, USA and ${ }^{7}$ Department of Medicine, University of Michigan, Ann Arbor, MI, USA
\end{abstract}

Correspondence and offprint requests to: Kamyar Kalantar-Zadeh; E-mail: kamkal@ucla.edu

\begin{abstract}
Background. Recent observational studies and a controlled trial suggest more favorable outcomes upon later dialysis initiation in chronic kidney disease. The role of estimated glomerular filtration rate (eGFR) in predicting outcome at reinitiation of dialysis in failed kidney transplant recipients is unclear.

Methods. Five-year data in a large dialysis organization was linked to the 'Scientific Registry of Transplant Recipients' to identify 747 failed kidney transplant patients with CKD Stage 5, who had restarted dialysis therapy. A propensity score for early (eGFR $>10.5 \mathrm{~mL} / \mathrm{min} / 1.73 \mathrm{~m}^{2}$ ) versus late reinitiation of dialysis was fit by logistic regression. The mortality hazard ratio (HR) was estimated across tertiles of the fitted score.

Results. Patients were $44 \pm 14$ years old and included $42 \%$ women. Male gender \{odds ratio (OR), [95\% confidence interval (CI)]: $1.82(1.22-2.73)\}$, diabetes mellitus [OR: $1.75(1.14-2.68)]$ and peripheral vascular disease [OR: 3.55 (1.17-10.77)] were associated with higher odds of early dialysis reinitiation. Each $\mathrm{mL} / \mathrm{min} / 1.73 \mathrm{~m}^{2}$ higher eGFR was associated with $6 \%$ higher death risk in unadjusted model [HR: 1.06 (1.01-1.11)], and although not significant in fully adjusted models [HR: 1.02 (0.961.07)], it was significant in some subgroups including women and younger patients. The death HR of higher eGFR across lowest to highest tertiles of propensity score of early dialysis initiation (corresponding healthiest to sickest patients) were $1.10(0.98-1.24), 1.00(0.91-1.10)$ and $0.99(0.92-1.07)$, respectively ( $\mathrm{P}$ for trend $<0.05$ ), indicating a trend toward higher mortality risk with earlier dialysis initiation in the healthiest patients.

Conclusions. Earlier return to dialysis therapy in failed kidney transplant patients tends to correlate with worse dialysis survival especially among healthiest and younger patients and women. Additional studies need to verify these findings.
\end{abstract}

Keywords: eGFR; failed kidney; initiation of dialysis; kidney transplantation; mortality

\section{Introduction}

In 1997, the US National Kidney Foundation-Kidney Disease Outcome Quality Initiative (NKF-KDOQI) recommended that dialysis should start at a urea clearance (renal $K t / V_{\text {urea }}$ ) of $<2.0 /$ week [1]. This corresponds to a glomerular filtration rate (GFR) of $\sim 10.5 \mathrm{~mL} / \mathrm{min} / 1.73 \mathrm{~m}^{2}$. The updated guidelines from 2006 suggest that dialysis should start before chronic kidney disease (CKD) Stage 5 (GFR $<15 \mathrm{~mL} / \mathrm{min} / 1.73 \mathrm{~m}^{2}$ ) if patients have symptoms believed to be related to a combination of existing comorbidities and insufficient renal function [2]. In Europe, guidelines from 2002 recommend that dialysis should be started when the GFR is between 8 and $10 \mathrm{~mL} / \mathrm{min} /$ $1.73 \mathrm{~m}^{2}$ [3]. However, the latter guideline has recently been revised and suggests that 'the majority of patients will be symptomatic and need to start dialysis with GFR in the range of $9-6 \mathrm{~mL} / \mathrm{min} / 1.73 \mathrm{~m}^{2},[4]$. Data from the US Renal Data System (USRDS) between 1996 and 2008 showed that the proportion of patients initiating hemodialysis (HD) with an estimated GFR (eGFR) $>10 \mathrm{~mL} / \mathrm{min} /$ $1.73 \mathrm{~m}^{2}$ increased from 20 to $52 \%$ and those with a starting eGFR of $\geq 15 \mathrm{~mL} / \mathrm{min} / 1.73 \mathrm{~m}^{2}$ increased from 4 to $17 \%[5,6]$. Interestingly, most of the recent observational trials and a landmark randomized controlled trial failed to show a survival benefit of early initiation of dialysis in CKD patients [5, 7-18].

Contrary to CKD patients, only limited data are available in failed kidney transplant recipients. Failed kidney transplant recipients start dialysis in a worse clinical condition compared to CKD patients in general $[19,20]$ and also have worse survival on HD [19] and in some cases on peritoneal dialysis [21-26]. The incidence and prevalence of end-stage renal disease (ESRD) due to posttransplant complications have increased substantially from 0.3/million and 3.2/1 million between 1996 and 1998 to 1.3/million and 4.9/1 million between 2006 and 2008,

(C) The Author 2012. Published by Oxford University Press on behalf of ERA-EDTA. All rights reserved.

For Permissions, please e-mail: journals.permissions@oup.com 
respectively [27]. Dialysis after kidney allograft loss (DAGL) is among the top five leading individual causes of dialysis initiation after diabetes mellitus, hypertension, renovascular disease and unknown causes of ESRD. In $2007,4.1 \%$ of new US dialysis patients initiated DAGL [28]. To the best of our knowledge, there is only one previous study assessing the association between eGFR at initiation of dialysis and mortality in DAGL patients [29]. In 2002, Gill et al., using USRDS data, examined DAGL in 4741 patients. Each $\mathrm{mL} / \mathrm{min} / 1.73 \mathrm{~m}^{2}$ increase in eGFR at reinitiation of dialysis was associated with a $4 \%$ increased risk of mortality on dialysis in failed kidney transplant patients [hazard ratio (HR): 1.04, 95\% confidence interval (CI): 1.02-1.06] [29]. Factors not considered as potential sources of bias in the study by Gill et al., who was conducted without propensity scoring, included patients' comorbidity, age, gender and other relevant confounders. In the present study, we used a propensity score approach to examine the association of the level of eGFR at the initiation of dialysis [early (eGFR $>10.5 \mathrm{~mL} / \mathrm{min} /$ $1.73 \mathrm{~m}^{2}$ ) versus late reinitiation (eGFR $\leq 10.5 \mathrm{~mL} / \mathrm{min} /$ $\left.1.73 \mathrm{~m}^{2}\right)$ ] with subsequent mortality on dialysis in DAGL patients.

\section{Materials and methods}

\section{Patients}

We linked data on all DAGL patients who underwent maintenance HD or peritoneal dialysis treatment from July 2001 to June 2006 in one of the outpatient dialysis facilities of a US-based large dialysis organization (DaVita Inc., prior to its acquisition of former Gambro dialysis facilities) with patients listed in the 'Scientific Registry of Transplant Recipients' (SRTR) up to 2007. The study was approved by the Institutional Review Boards of both the Los Angeles Biomedical Research Institute at Harbor-UCLA and DaVita Clinical Research. Inclusion criteria were patients who had been undergoing dialysis for at least 90 days, whose dialysis initiation date was listed in USRDS within 30 days of their graft failure date (as listed in SRTR), and who had their initial eGFR level captured in USRDS. The four-variable Modification of Diet in Renal Disease (MDRD) equation was used to assess the eGFR in our present study. In this study, we identified failed transplant recipients who reinitiated dialysis therapy with an eGFR $<15 \mathrm{~mL} / \mathrm{min} / 1.73 \mathrm{~m}^{2}$ to be consistent with CKD Stage 5 definition.

\section{Clinical and demographic measures}

To minimize measurement variability, all repeated measures for each patient during any given calendar quarter, i.e. over a 13-week interval, were averaged and the summary estimate was used in all models. Average values were obtained from up to 20 calendar quarters (q1 through q20) for each laboratory and clinical measure for each patient for up to 6 years of follow-up. The first (baseline) studied quarter for each patient was the calendar quarter in which the patient's dialysis vintage was $>90$ days. Demographic data and details of medical history were collected, with information on age, gender, race, type of insurance, marital status, height and post-HD dry weight [to calculate averaged body mass index (BMI)]. We captured the date and the cause of death from USRDS.

\section{Laboratory measures}

Most laboratory values were measured monthly including serum urea, creatinine, albumin, calcium, phosphorus, bicarbonate and total ironbinding capacity (TIBC). Serum ferritin and intact parathyroid hormone were measured at least quarterly. Hemoglobin was measured at least monthly in essentially all patients and weekly to bi-weekly in most patients. Most blood samples were collected pre-dialysis with the exception of post-dialysis serum urea nitrogen to calculate urea kinetics.

\section{Statistical methods}

Data were summarized with descriptive statistics as appropriate. Survival analysis to calculate HRs and $95 \%$ CI of all-cause mortality employed Cox proportional hazards regression. For mortality analysis, we censored for loss of follow-up and re-transplantation in all survival analyses. Logistic regression model was employed to estimate the odds ratio (OR) and $95 \% \mathrm{CI}$ of early (eGFR $>10.5 \mathrm{~mL} / \mathrm{min} / 1.73 \mathrm{~m}^{2}$ ) versus late initiation (eGFR $\leq 10.5 \mathrm{~mL} / \mathrm{min} / 1.73 \mathrm{~m}^{2}$ ) of dialysis. Multivariate logistic regression model was constructed based on theoretical consideration using the available data from literature and results of our univariate analysis. We adjusted for age, gender, BMI, race, type of insurance, comorbidities (diabetes, atherosclerotic heart disease, peripheral vascular disease), serum bicarbonate and normalized protein catabolic ratio as an indicator of daily protein intake, also known as the normalized protein nitrogen appearance.

The propensity score method was used to account for the confounding effects arising from differences in clinical characteristics of patients in whom dialysis was started early (eGFR $>10.5 \mathrm{~mL} / \mathrm{min} / 1.73 \mathrm{~m}^{2}$ ) versus late (eGFR $\leq 10.5 \mathrm{~mL} / \mathrm{min} / 1.73 \mathrm{~m}^{2}$ ). First, factors that seemed to influence the likelihood of early dialysis initiation were studied using logistic regression. On the basis of this logistic regression model, we calculated propensity scores of early dialysis initiation [30, 31]. Multivariate logistic regression model to derive the propensity score for choosing early dialysis initiation the outcome had the area under the receiver operating characteristic curve of 0.65 , denoting moderate predictive discrimination with respect to the outcome. Three propensity score strata were created using the 33rd and 66th percentiles as cutoff points.

For each Cox regression analysis, three levels of multivariate adjustment were examined: (i) an unadjusted model that included start eGFR as the predictor; (ii) adjusted models that included the start eGFR as the predictor plus age, gender and diabetes and (iii) fully adjusted models that included start eGFR as the predictor plus age, gender, diabetes, serum albumin, BMI and presence of atherosclerotic heart disease. As sensitivity analysis, we constructed a more parsimonious model that included start eGFR as the predictor and adjusted for the propensity score. Restricted cubic spline graphs were utilized as exploratory data analysis strategies to illustrate systematic relations between initiation level of eGFR and mortality [32]. We have performed subgroup analysis in patients categorized by relevant clinical characteristics. Proportional hazard assumptions were tested using Schoenfeld residuals. All analyses were carried out with STATA version 11.1 (STATA Corporation, College Station, TX)

\section{Results}

The original 5-year (July 2001 to June 2006) national database of all DaVita patients included 164789 adult subjects. Of 16758 DaVita patients who were identified in the SRTR database, 12986 had a functioning kidney transplant. From the remaining 3772 patients with DAGL, we excluded 2897 patients with graft failure whose dialysis initiation date listed in USRDS was $>30$ days after their graft failure date listed in SRTR and patients who did not have initiation eGFR level in USRDS $(n=21)$ or eGFR was $>15 \mathrm{~mL} / \mathrm{min} / 1.73 \mathrm{~m}^{2}$ $(n=107)$. We examined the remaining 747 patients who underwent dialysis after loss of kidney transplant during the observation period and who were followed until death, re-transplantation, loss of follow-up or survival until 30 June 2007 (Figure 1). There were 181 deaths (24.2\%) and the median follow-up time was 1185 days (interquartile range: 692-1854 days).

Table 1 shows the clinical, demographic and laboratory characteristics of the 747 dialysis patients comparing the early $\left(\mathrm{eGFR}>10.5 \mathrm{~mL} / \mathrm{min} / 1.73 \mathrm{~m}^{2}\right)$ and late initiation (eGFR $\leq 10.5 \mathrm{~mL} / \mathrm{min} / 1.73 \mathrm{~m}^{2}$ ) subgroups. Patients in the early initiation subgroup were more likely to be men, 


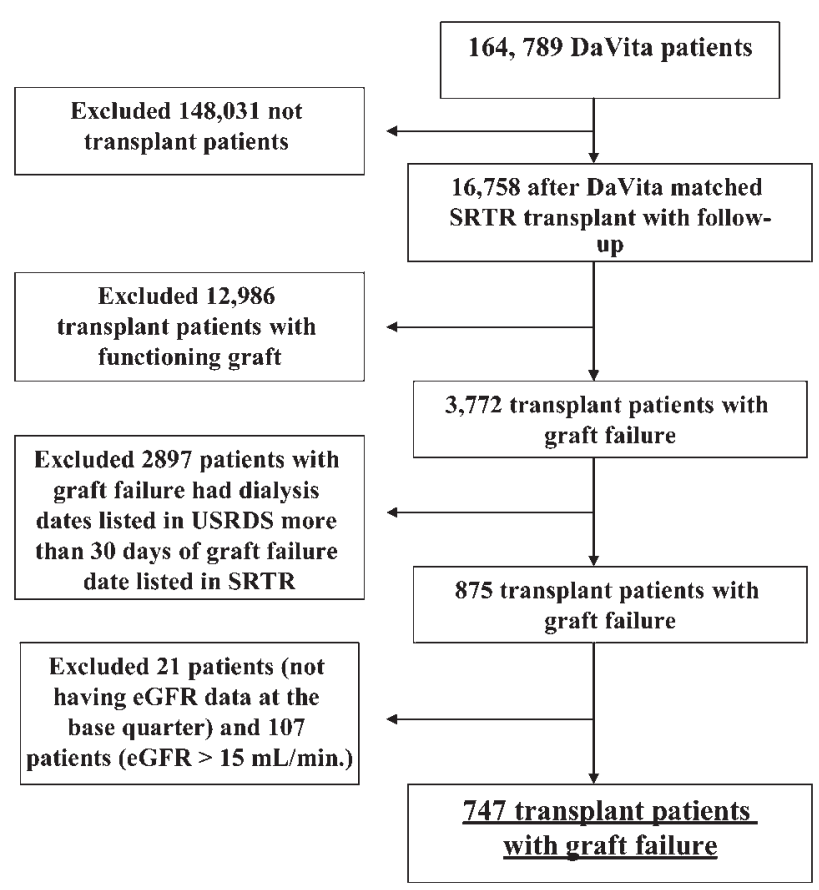

Fig. 1. Flow chart of patients' selection.

insured by Medicare and to be diabetic and have atherosclerotic heart disease, peripheral vascular disease and lower TIBC and phosphorous levels.

Table 2 shows the OR of dialysis start at higher (eGFR $>10.5 \mathrm{~mL} / \mathrm{min} / 1.73 \mathrm{~m}^{2}$ ) versus lower (eGFR $<10.5 \mathrm{~mL} /$ $\mathrm{min} / 1.73 \mathrm{~m}^{2}$ ) eGFR using multivariate logistic regression analysis. Male gender, presence of diabetes and peripheral vascular disease were associated with increased risk of early initiation of dialysis.

Table 3 shows the HR of death using eGFR upon return to dialysis as the primary predictor. Figure $2 \mathrm{~A}$ shows the cubic spline model for the unadjusted association of the eGFR at the start of dialysis with mortality. In an unadjusted model, each $1 \mathrm{~mL} / \mathrm{min} . / 1.73 \mathrm{~m}^{2}$ higher eGFR at dialysis therapy reinitiation was associated with a $6 \%$ higher risk of death (HR: $1.06,95 \%$ CI: 1.01-1.11) (Table 3). Figure 2B shows the cubic spline model for the fully adjusted association of the eGFR at the start of dialysis with mortality. In the fully adjusted model, eGFR at the start of dialysis was not associated with the risk of death (HR: 1.02, 95\% CI: 0.96-1.07) (Table 3). In a model adjusted for the propensity score, each $1 \mathrm{~mL} / \mathrm{min}$./ $1.73 \mathrm{~m}^{2}$ higher eGFR (indicating earlier dialysis reinitiation) was not associated with greater survival (HR: 1.02, 95\% CI: 0.96-1.07).

Table 4 shows the death HR during dialysis therapy based on the starting eGFR as predictor across the tertiles of the propensity score. The eGFR level at the start of dialysis showed an increasing trend toward higher risk of death in the group with low likelihood for dialysis initiation at higher eGFR (HR: 1.10, 95\% CI: 0.98-1.24), but not in the moderate (HR: 1.00, 95\% CI: $0.91-1.10$ ) or high (HR: $0.99,95 \%$ CI: $0.92-$
1.07) likelihood groups ( $\mathrm{P}$ for trend across three tertiles $<0.05$ ).

Figure 3 shows unadjusted (Panel A) and fully adjusted (Panel B) death HR (and 95\% CI) associated with eGFR across various patient groups. The point estimates were $>1$ in some subgroups (women and young patients), representing a higher risk of death in patients with early initiation of dialysis in these subgroups.

\section{Discussion}

In 747 failed kidney transplant recipients who returned to dialysis therapy between 2001 and 2006, a higher eGFR upon reinitiation of dialysis treatment exhibited a trend toward higher mortality risk especially among the healthiest subgroups, including patients with a lower propensity score of early dialysis initiation, women and younger individuals. Even though patients with early initiation of dialysis appeared sicker (more diabetic and heart disease patients with lower BMI), there was no survival advantage of earlier dialysis therapy at higher eGFR levels in any group. These data may have important clinical and public health policy implications in the long-term management of renal transplant recipients with chronic allograft nephropathy especially with regard to the recommendations for the timing of return to dialysis therapy.

Similar data from CKD patients showed controversial results [33]. From the mid-1970s, some observational studies supported the early initiation of dialysis in CKD patients. However, these studies were small and mainly not adjusted for age and comorbidities, which were different between the early and late subgroups [34-40]. Despite the weak evidence, early initiation was accepted and it was common practice until recently. More recent studies, including a randomized controlled trial, did not support early initiation of dialysis in CKD patients [5, $8,9,12,15-18]$. The large multicenter trial from Netherland, the Netherlands Cooperative Study on the Adequacy of Dialysis, was the first observational study which casts doubt on the advantages of early dialysis initiation [7]. Korevaar et al. found a small beneficial effect of early dialysis initiation; they observed a gain in survival time of 2.5 months in the first 3 years after the start of dialysis. However, this advantage could have been overestimated because of lead-time bias [7]. This bias was the first potential explanation for previous smaller studies' opposite results. In 2003, Beddhu et al. [9] reported that higher eGFR was associated with higher risk of death, but in a subgroup of patients with measured creatinine clearance, there was no association with mortality. Traynor et al. [8], on the other hand, reported that higher creatinine clearance at initiation of dialysis was associated with elevated mortality risk. The largest observational study from the USA found a dose-dependent increase in mortality associated with earlier dialysis initiation. After correcting for other factors, compared with those with an eGFR of $>5$ to $10 \mathrm{~mL} / \mathrm{min} / 1.73 \mathrm{~m}^{2}$ at the start of dialysis, patients 
Table 1. Baseline characteristics of 747 failed kidney transplant patients who returned to dialysis therapy based on the timing of dialysis reinitiation, i.e. late $\left(\mathrm{eGFR} \leq 10.5 \mathrm{~mL} / \mathrm{min} / 1.73 \mathrm{~m}^{2}\right)$ versus early return to dialysis $\left(\mathrm{eGFR}>10.5 \mathrm{~mL} / \mathrm{min} / 1.73 \mathrm{~m}^{2}\right)^{\mathrm{a}}$

\begin{tabular}{|c|c|c|c|}
\hline & $\mathrm{eGFR} \leq 10.5 \mathrm{~mL} / \mathrm{min} / 1.73 \mathrm{~m}^{2}$ & $\mathrm{eGFR}>10.5 \mathrm{~mL} / \mathrm{min} / 1.73 \mathrm{~m}^{2}$ & P-value \\
\hline$N(\%)$ & $531(71)$ & $216(29)$ & N/A \\
\hline Deaths $(n)$ (crude death rate \%) & $124(23)$ & $57(26)$ & 0.38 \\
\hline Age $($ years $)($ mean $\pm S D)$ & $43 \pm 13$ & $45 \pm 16$ & 0.11 \\
\hline Gender ( $\%$ women) & $244(46)$ & $68(31)$ & $<0.001$ \\
\hline Weight $(\mathrm{kg})($ mean $\pm \mathrm{SD})$ & $73.3 \pm 19.8$ & $72.8 \pm 19.2$ & 0.77 \\
\hline Estimated lean body mass $(\mathrm{kg})($ mean $\pm \mathrm{SD})$ & $50.5 \pm 8.3$ & $49.5 \pm 8.2$ & 0.25 \\
\hline Peritoneal dialysis $(n)(\%)$ & $82(15)$ & $39(18)$ & 0.38 \\
\hline Transplant vintage (months) [median (IQR)] & $51(40-70)$ & $56(45-73)$ & 0.02 \\
\hline \multicolumn{4}{|l|}{ Race $(\%)$} \\
\hline African-American & 31 & 28 & 0.43 \\
\hline White & 45 & 49 & 0.25 \\
\hline Hispanic & 15 & 13 & 0.52 \\
\hline Asian & 3 & 3 & 0.91 \\
\hline \multicolumn{4}{|l|}{ Primary insurance $(\%)$} \\
\hline Medicaid & 4 & 3 & 0.56 \\
\hline Private & 10 & 5 & 0.03 \\
\hline Other & 23 & 22 & 0.64 \\
\hline \multicolumn{4}{|l|}{ Marital status (\%) } \\
\hline Married & 37 & 44 & 0.10 \\
\hline Divorced & 5 & 6 & 0.96 \\
\hline Single & 33 & 32 & 0.85 \\
\hline Widowed & 2 & 1 & 0.37 \\
\hline \multicolumn{4}{|l|}{ Dialysis vintage $(\%)$} \\
\hline 0-6 Months & 10 & 17 & 0.01 \\
\hline 6-24 Months & 23 & 24 & 0.83 \\
\hline 2-5 Years & 27 & 20 & 0.05 \\
\hline$>5$ Years & 34 & 34 & 0.90 \\
\hline \multicolumn{4}{|l|}{ Comorbid conditions $(\%)$} \\
\hline Diabetes mellitus & 28 & 44 & $<0.001$ \\
\hline Cancer & 2 & 1 & 0.28 \\
\hline Chronic obstructive pulmonary disease & 1 & 2 & 0.44 \\
\hline Cerebrovascular disease & 1 & 2 & 0.22 \\
\hline History of hypertension & 72 & 68 & 0.18 \\
\hline Other heart diseases & 1 & 3 & 0.17 \\
\hline Peripheral vascular disease & 2 & 5 & 0.03 \\
\hline Smoker & 4 & 6 & 0.33 \\
\hline \multicolumn{4}{|c|}{ Serum or blood measurement (during the first dialysis quarter) } \\
\hline Creatinine at quarter base $(\mathrm{mg} / \mathrm{dL})($ mean $\pm \mathrm{SD})$ & $10.2 \pm 3.5$ & $9.2 \pm 3.9$ & 0.002 \\
\hline Creatinine at quarter base $+1(\mathrm{mg} / \mathrm{dL})($ mean $\pm \mathrm{SD})$ & $10.9 \pm 3.5$ & $10.2 \pm 4.0$ & 0.05 \\
\hline Blood hemoglobin $(\mathrm{g} / \mathrm{dL})($ mean $\pm \mathrm{SD})$ & $11.4 \pm 1.7$ & $11.7 \pm 1.6$ & 0.08 \\
\hline Albumin $(\mathrm{g} / \mathrm{dL})($ mean $\pm \mathrm{SD})$ & $3.73 \pm 0.48$ & $3.69 \pm 0.56$ & 0.44 \\
\hline $\mathrm{TIBC}(\mathrm{mg} / \mathrm{dL})($ mean $\pm \mathrm{SD})$ & $204 \pm 47$ & $194 \pm 45$ & 0.02 \\
\hline Bicarbonate $(\mathrm{mmol} / \mathrm{L})($ mean $\pm \mathrm{SD})$ & $22.0 \pm 3.6$ & $22.5 \pm 3.2$ & 0.17 \\
\hline Calcium $(\mathrm{mg} / \mathrm{dL})($ mean $\pm \mathrm{SD})$ & $9.2 \pm 0.8$ & $9.2 \pm 0.8$ & 0.94 \\
\hline Phosphorous (mg/dL) (mean $\pm \mathrm{SD})$ & $6.2 \pm 1.8$ & $5.9 \pm 1.6$ & 0.04 \\
\hline Ferritin $(\mathrm{ng} / \mathrm{mL})[$ median $(\mathrm{IQR})]$ & $376(199-736)$ & $393(192-679)$ & 0.82 \\
\hline Protein catabolic rate $(\mathrm{g} / \mathrm{kg} /$ day $)($ mean $\pm \mathrm{SD})$ & $0.95 \pm 0.29$ & $0.92 \pm 0.27$ & 0.17 \\
\hline $\mathrm{WBC}\left(\times 10^{3} / \mu \mathrm{L}\right)($ mean $\pm \mathrm{SD})$ & $7.4 \pm 2.7$ & $7.4 \pm 2.2$ & 0.99 \\
\hline Lymphocyte $(\%$ of total WBC) $($ mean \pm SD) & $21 \pm 9$ & $22 \pm 10$ & 0.84 \\
\hline
\end{tabular}

${ }^{\mathrm{a}} \mathrm{IQR}$, interquartile range; WBC, white blood cell.

who initiated dialysis with a higher eGFR experienced a $44 \%$ greater mortality risk, whereas those who initiated dialysis at the lowest eGFR $(<5 \mathrm{~mL} / \mathrm{min} /$ $1.73 \mathrm{~m}^{2}$ ) had a $12 \%$ lower risk of death [15]. Similar results were reported from the largest observational study from Europe [12]. Data from randomized controlled trials which establish the optimal timing for the initiation of dialysis were lacking until 2010, when the
Initiating Dialysis Early and Late (IDEAL) study was published [16, 18]. In this study, patients were randomly assigned either to commence dialysis when the eGFR was $10.0-14.0 \mathrm{~mL} / \mathrm{min} / 1.73 \mathrm{~m}^{2}$ (early-start group) or to continue to receive routine medical care and commence dialysis when the eGFR was 5.0-7.0 $\mathrm{mL} / \mathrm{min} / 1.73 \mathrm{~m}^{2}$ (late-start group) [18]. During a median follow-up of 3.6 years, $37.6 \%$ of early starters 
and $36.6 \%$ of late starters died (HR for early initiation 1.04, 95\% CI: 0.83-1.30; $\mathrm{P}=0.75)$ [16]. Although randomized trials provide the best type of evidence, a question always remains over the generalizability of their results [4, 41]. The mean actual eGFR at the start of dialysis in the IDEAL trial differed only slightly between the two groups $(2.2 \mathrm{~mL} / \mathrm{min}$ by the Cockcroft-Gault equation and $1.8 \mathrm{~mL} / \mathrm{min}$ by the MDRD equation) [42]. This is a considerably smaller difference compared to what was prespecified by the study protocol and casts doubt on the ability of the study to answer the question it was meant to address.

The main concern of observational studies including ours is the difference between the clinical characteristics and dialysis indications of the early and late initiation groups. Patients with early dialysis initiation were more likely to be men and diabetic, have severe heart failure or coronary heart disease, are less likely to have

Table 2. OR of dialysis reinitiation at higher (eGFR $>10.5 \mathrm{~mL} / \mathrm{min} /$ $1.73 \mathrm{~m}^{2}$ ) versus lower (eGFR $<10.5 \mathrm{~mL} / \mathrm{min} / 1.73 \mathrm{~m}^{2}$ ) using multivariate logistic regression analysis, indicating the likelihood of earlier return to dialysis therapy in 747 failed kidney transplant patients ${ }^{\mathrm{a}}$

\begin{tabular}{lll}
\hline & OR $(95 \% \mathrm{CI})$ & P-value \\
\hline Age $(+1$ year) & $1.00(0.98-1.01)$ & 0.59 \\
Male versus female (reference) & $1.82(1.22-2.73)$ & 0.003 \\
BMI $\left(+1 \mathrm{~kg} / \mathrm{m}^{2}\right)$ & $0.97(0.94-1.01)$ & 0.13 \\
AA race versus White race (reference) & $1.00(0.64-1.56)$ & 0.99 \\
Hispanic race versus White race (reference) & $0.91(0.52-1.60)$ & 0.75 \\
Asian race versus White race (reference) & $1.40(0.48-4.08)$ & 0.54 \\
Medicaid versus Medicare (reference) & $0.92(0.37-2.30)$ & 0.86 \\
Private insurance versus Medicare & $0.48(0.23-1.02)$ & 0.06 \\
(reference.) & & \\
Other insurance versus Medicare & & \\
(reference) & $0.85(0.52-1.38)$ & 0.51 \\
Presence of diabetes mellitus & $1.75(1.14-2.68)$ & 0.01 \\
Presence of atherosclerotic heart disease & $1.71(0.75-3.90)$ & 0.20 \\
Presence peripheral vascular disease & $3.55(1.17-10.77)$ & 0.03 \\
$\begin{array}{l}\text { Bicarbonate }(+1 \text { mmol/L) } \\
\text { nPCR }(+1 \mathrm{~g} / \mathrm{kg} / \text { day })\end{array}$ & $1.02(0.96-1.08)$ & 0.54 \\
\hline
\end{tabular}

${ }^{\mathrm{a}} \mathrm{AA}$, African-American; nPCR, normalized protein catabolic ratio. glomerulonephritis or polycystic kidney disease and have lower serum albumin level and more comorbidity and in summary, they are sicker patients $[5,9,14,17]$. In our DAGL patients, we found similar results. To handle this potential bias, we used a propensity score in our analysis and we performed subgroup analyses.

A higher eGFR at dialysis initiation was associated with a trend toward higher mortality in healthier subgroups. It is possible that in healthier patients, early dialysis initiation may in fact be harmful. However, eGFR at dialysis initiation was not associated with mortality in sicker subgroups. In these patients, (male, diabetic with peripheral vascular disease) there may be an advantage for early initiation, but further studies are needed to answer this question.

There are some potential factors which can contribute to increased risk of mortality with early dialysis initiation. Thrice-weekly HD treatment may lead to subtle but cumulative mechanical and oxidative stress on the cardiovascular system and engender hemodynamic instability. Burton et al. recently showed that HD-induced myocardial stunning is common and may contribute to the development of heart failure and increased mortality in HD patients [43, 44]. In spite of the advances made with more biocompatible membranes, bioincompatibility still remains a problem which may contribute to elevated inflammation/infection and oxidative stress [45]. Moreover, after initiation of dialysis, infection rates are extremely high. Between 1996 and 2001 among a US Medicare cohort of patients who recently started dialysis, the 1-year incidence of infection-related hospitalizations was $32 \%$ for those who received HD and $24 \%$ for those who received peritoneal dialysis; the 3 -year incidence exceeded $50 \%$ in both groups [46]. Whereas in the HEMO study, most infection-related hospitalizations were not attributed to vascular access [47], the frequency of access-related infectious hospitalizations was disproportionately higher among patients with catheters compared to grafts or fistulas [47]. Furthermore, there may be repeated bouts of acute tubular necrosis by

Table 3. Death HR using eGFR at dialysis reinitiation in 747 failed kidney transplant patients ${ }^{\mathrm{a}}$

\begin{tabular}{|c|c|c|c|c|c|c|}
\hline & \multicolumn{2}{|l|}{ Unadjusted model } & \multicolumn{2}{|l|}{ Adjusted model ${ }^{\mathrm{b}}$} & \multicolumn{2}{|c|}{ Fully adjusted model ${ }^{\mathrm{c}}$} \\
\hline & $\mathrm{HR}(95 \% \mathrm{CI})$ & P-value & $\mathrm{HR}(95 \% \mathrm{CI})$ & P-value & HR $(95 \% \mathrm{CI})$ & P-value \\
\hline eGFR (each $1 \mathrm{~mL} / \mathrm{min} / 1.73 \mathrm{~m}^{2}$ higher) & $1.06(1.01-1.11)$ & 0.02 & $1.03(0.98-1.09)$ & 0.22 & $1.02(0.97-1.07)$ & 0.54 \\
\hline Early versus late reinitiation of dialysis & $1.27(0.93-1.74)$ & 0.14 & $1.03(0.74-1.43)$ & 0.86 & $0.95(0.68-1.33)$ & 0.77 \\
\hline \multicolumn{7}{|c|}{ HR of death for other covariates in the above model } \\
\hline Age (each 1 year increase) & N/A & N/A & $1.03(1.02-1.04)$ & $<0.001$ & $1.03(1.01-1.04)$ & $<0.001$ \\
\hline Gender (male versus female) & N/A & $\mathrm{N} / \mathrm{A}$ & $1.11(0.82-1.50)$ & 0.50 & $1.24(0.91-1.69)$ & 0.18 \\
\hline Presence of diabetes & N/A & N/A & $1.86(1.36-2.55)$ & $<0.001$ & $1.66(1.20-2.29)$ & 0.002 \\
\hline Serum albumin (each $1 \mathrm{~g} / \mathrm{dL}$ increase) & N/A & $\mathrm{N} / \mathrm{A}$ & N/A & N/A & $0.44(0.33-0.59)$ & $<0.001$ \\
\hline BMI (each $1 \mathrm{~kg} / \mathrm{m}^{2}$ increase) & N/A & $\mathrm{N} / \mathrm{A}$ & N/A & N/A & $0.99(0.96-1.02)$ & 0.38 \\
\hline Presence atherosclerotic heart disease & N/A & N/A & N/A & N/A & $2.23(1.44-3.46)$ & $<0.001$ \\
\hline
\end{tabular}

${ }^{a}$ The early versus late dialysis reinitiation dichotomy is based on eGFR $>10.5$ versus $\leq 10.5 \mathrm{~mL} / \mathrm{min} / 1.73 \mathrm{~m}^{2}$. N/A, not applicable.

${ }^{\mathrm{b}}$ Model adjusted for age, gender and diabetes.

${ }^{\mathrm{c}}$ Model adjusted for age, gender, diabetes, serum albumin, BMI and presence atherosclerotic heart disease. 

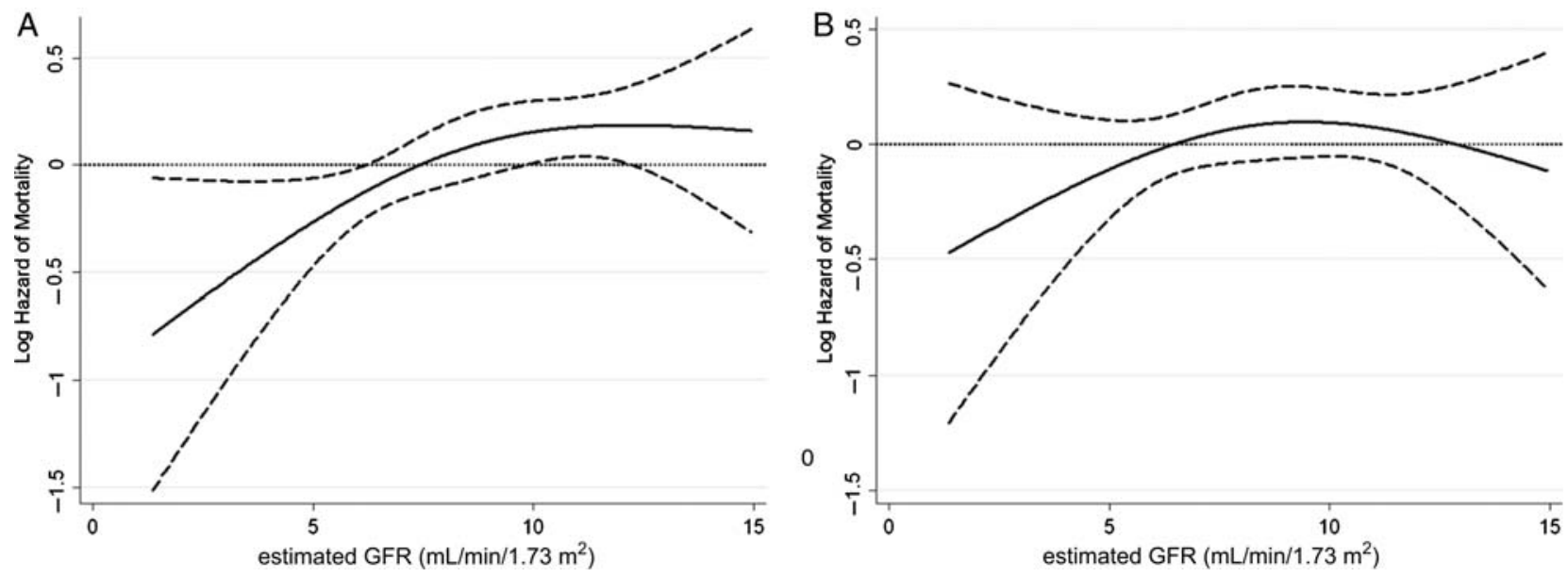

Fig. 2. HR (95\% CIs) of death across the entire range of the eGFR level using unadjusted (A) and fully adjusted (B) Cox regression analyses in 747 long-term failed transplant patients who restarted HD therapy.

Table 4. HR of death using eGFR at dialysis reinitiation as the death predictor across the tertiles of the propensity score (PS) that reflects the propensity to earlier likelihood of return to dialysis therapy ${ }^{\mathrm{a}}$

\begin{tabular}{|c|c|c|c|c|c|c|}
\hline \multirow[t]{2}{*}{ PS tertiles } & \multicolumn{2}{|l|}{ Unadjusted model } & \multicolumn{2}{|l|}{ Adjusted model $^{\mathrm{b}}$} & \multicolumn{2}{|c|}{ Fully Adjusted model $^{c}$} \\
\hline & HR $(95 \% \mathrm{CI})$ & P-value & $\mathrm{HR}(95 \% \mathrm{CI})$ & P-value & $\mathrm{HR}(95 \% \mathrm{CI})$ & P-value \\
\hline Low likelihood of early initiation $(n=249)$ & $1.05(0.94-1.17)$ & 0.37 & $1.09(0.98-1.22)$ & 0.11 & $1.10(0.98-1.24)$ & 0.10 \\
\hline Moderate likelihood of early initiation $(n=249)$ & $1.01(0.92-1.11)$ & 0.87 & $1.02(0.93-1.12)$ & 0.64 & $1.00(0.91-1.10)$ & 0.99 \\
\hline High likelihood of early initiation $(n=249)$ & $1.02(0.95-1.09)$ & 0.56 & $1.00(0.93-1.08)$ & 0.95 & $0.99(0.92-1.07)$ & 0.82 \\
\hline
\end{tabular}

${ }^{\text {a } P S, ~ p r o p e n s i t y ~ s c o r e . ~}$

${ }^{\mathrm{b}}$ Model adjusted for age, gender and diabetes.

${ }^{\mathrm{c}}$ Model adjusted for age, gender, diabetes, serum albumin, BMI and presence atherosclerotic heart disease.

A

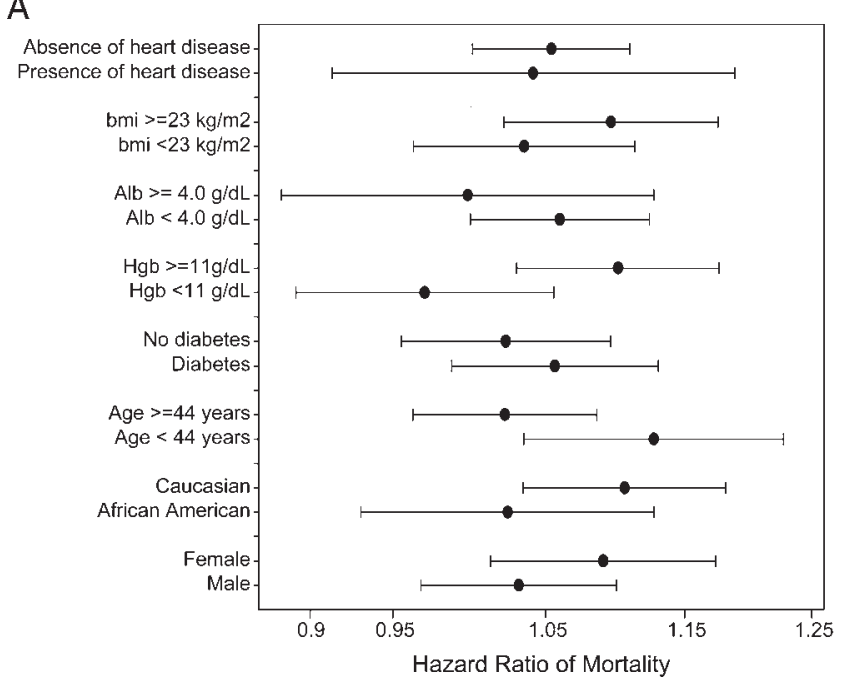

B

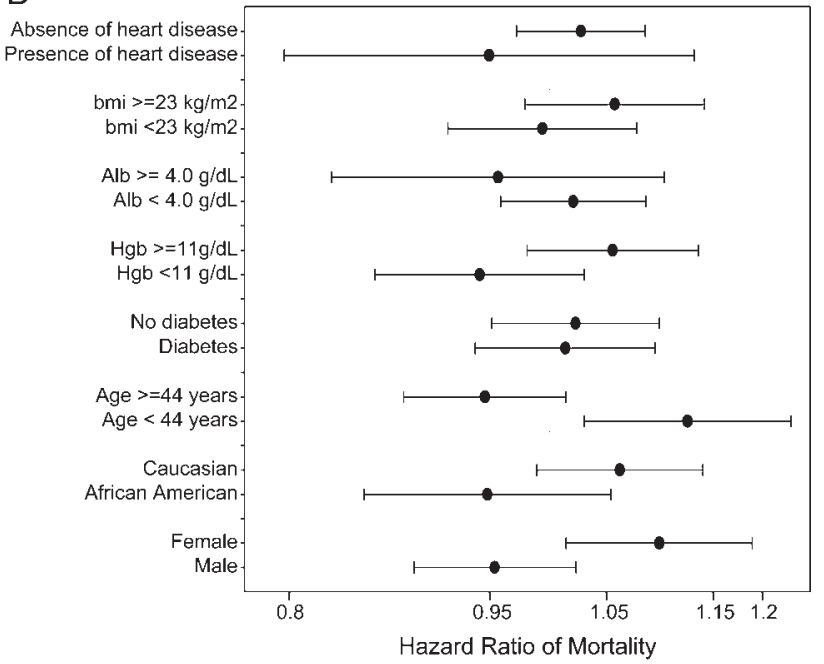

Fig. 3. Multivariate analysis of unadjusted (A) and fully adjusted (B) Cox regression models showing the HR (and $95 \%$ CI as error bars) of death using eGFR at dialysis reinitiation as the death predictor (for each $1 \mathrm{~mL} / \mathrm{min} . / 1.73 \mathrm{~m}^{2}$ higher eGFR) across different subgroups of patients. 
lowering the blood pressure during each HD session [48], resulting in faster loss of residual kidney function and frequent ischemic events upon hypotensive episodes. Exposure to toxic medications may also play role. Patient anxiety which accompanies each HD treatments, along with post-HD fatigue and lightheadedness, may also be harmful [49]. Peritoneal dialysis may be harmful in other ways including substantial protein loss and frequent peritonitis.

There is another factor, which can explain the association of high eGFR and mortality. The eGFR is an inaccurate measure of true GFR in Stage 5 CKD and that it, more accurately, reflects muscle mass (sarcopenia) - not detectable by BMI. High eGFR in Stage 5 CKD largely reflects sarcopenia, not higher renal function [50]. Sarcopenia is in turn a predictor of poor outcomes for patients on HD [51]. The association of high eGFR and mortality might be due to the presence of sarcopenia. Early start by creatinine clearance (a better measure of renal function in Stage $5 \mathrm{CKD}$ ) has no adverse effect on mortality risk [9].

Our study has several potential limitations. First, the reported associations do not prove causality. Second, transplant laboratory values (such as serum creatinine) and immunosuppressive and other medical regimens were not available in the SRTR and DaVita database. Third, unmeasured confounders might have an impact on our results. We only had 181 deaths in our cohort, which forced us to use parsimonious models. Fourth, we do not have data about dialysis center characteristics and therefore, we could not adjust for them. Fifth, we did not have the exact data as to which method was used to measure serum creatinine, therefore we did not adjust for the calibration used when we calculated eGFR. Sixth, another important source of bias and error in these studies is the use of eGFR instead of true creatinine clearance $(\mathrm{CrCl})$. Earlier studies showed that patients with low creatinine production were malnourished [52] and that CKD patients with protein-energy wasting including sarcopenia or low meat intake (due to diminished appetite and/or recommended low-protein diet) may have lower serum creatinine levels and perhaps lower creatinine clearance rates but paradoxically higher eGFR per MDRD at dialysis initiation [52]. Indeed, serum creatinine is a good indicator of muscle mass under stable conditions in HD patients [53-56]. Beddhu et al. [9] reported that higher initiation eGFR (MDRD), but not higher $\mathrm{CrCl}$, was associated with increased risk of death. Even though in our study we did not find a statistically significant association between higher eGFR at dialysis reinitiation and survival for the entire cohort, our statistical power is limited because among the 3772 failed transplant patients only 747 were included in this study; hence, our generalizability should be qualified. However, we found that higher eGFR was associated with higher death risk at least among women and younger patients. To our knowledge, this is one of the first studies to assess the association between the initiation eGFR and death on dialysis in DAGL patients. Strengths of this study are the relatively uniform dialysis treatment practice pattern across all DaVita clinics, the extensive laboratory and clinical data, the relatively long follow-up time and the multilevel adjustment including via propensity score, which include several important confounders.

\section{Conclusions}

In our present cohort of 747 incident HD patients with status post failed kidney transplant, earlier return to dialysis therapy tended to correlate with worse dialysis survival especially among the healthiest and younger patients and women. Whether earlier dialysis reinitiation in failed renal transplant recipients is harmful or not warrants additional studies.

Acknowledgements. We thank DaVita Clinical Research (DCR) for providing the clinical data, analysis and review for this research project.

Funding. The study was supported by KKZ's research grant from the American Heart Association grant (0655776Y). KKZ's other funding sources include the National Institute of Diabetes, Digestive and Kidney Disease of the National Institute of Health (R01 DK078106), a research grant from DaVita Clinical Research and a philanthropic grant from Mr Harold Simmons. M.Z.M. received grants from the National Developmental Agency (KTIA-OTKA-EU 7KP-HUMAN-MB08-A-81231) from the Research and Technological Innovation Fund and was also supported by Hungarian Kidney Foundation.

Conflict of interest statement. None declared.

\section{References}

1. National Kidney FoundationNKF-DOQI clinical practice guidelines for hemodialysis and peritoneal dialysis adequacy. Am J Kidney Dis 1997; 30: S67-S136.

2. National Kidney FoundationKDOQI Clinical Practice Guidelines and Clinical Practice Recommendations for 2006 Updates: hemodialysis adequacy, peritoneal dialysis adequacy and vascular access. $\mathrm{Am}$ J Kidney Dis 2006; 48: S1-S322.

3. The European Renal Association-European Dialysis and Transplant Association (ERA-EDTA)European best practice guidelines for haemodialysis. When to start dialysis. Nephrol Dial Transplant 2002; 17: S10-S11.

4. Tattersall J, Dekker F, Heimburger O et al. When to start dialysis: updated guidance following publication of the Initiating Dialysis Early and Late (IDEAL) study. Nephrol Dial Transplant 2011; 26: 2082-2086.

5. Rosansky SJ, Eggers P, Jackson K et al. Early start of hemodialysis may be harmful. Arch Intern Med 2011; 171: 396-403.

6. US renal Data SystemUSRDS 2009 Annual Data Report: Atlas of Chronic Kidney Disease and End Stage Renal Disease in the United States 2009Bethesda, MDNational Institutes of Health, National Institute of Diabetes and Digestive and Kidney Diseases

7. Korevaar JC, Jansen MA, Dekker FW et al. When to initiate dialysis: effect of proposed US guidelines on survival. Lancet 2001; 358: 1046-1050.

8. Traynor JP, Simpson K, Geddes CC et al. Early initiation of dialysis fails to prolong survival in patients with end-stage renal failure. $J$ Am Soc Nephrol 2002; 13: 2125-2132. 
9. Beddhu S, Samore MH, Roberts MS et al. Impact of timing of initiation of dialysis on mortality. $J$ Am Soc Nephrol 2003; 14: 2305-2312.

10. Kazmi WH, Gilbertson DT, Obrador GT et al. Effect of comorbidity on the increased mortality associated with early initiation of dialysis. Am J Kidney Dis 2005; 46: 887-896.

11. Wilson B, Harwood L, Locking-Cusolito $\mathrm{H}$ et al. Optimal timing of initiation of chronic hemodialysis?. Hemodial Int 2007; 11: 263-269.

12. Stel VS, Dekker FW, Ansell D et al. Residual renal function at the start of dialysis and clinical outcomes. Nephrol Dial Transplant 2009; 24: 3175-3182.

13. Sawhney S, Djurdjev O, Simpson K et al. Survival and dialysis initiation: comparing British Columbia and Scotland registries. Nephrol Dial Transplant 2009; 24: 3186-3192.

14. Lassalle M, Labeeuw M, Frimat L et al. Age and comorbidity may explain the paradoxical association of an early dialysis start with poor survival. Kidney Int 2010; 77: 700-707.

15. Wright S, Klausner D, Baird B et al. Timing of dialysis initiation and survival in ESRD. Clin J Am Soc Nephrol 2010; 5: $1828-1835$.

16. Cooper BA, Branley P, Bulfone L et al. A randomized, controlled trial of early versus late initiation of dialysis. $N$ Engl J Med 2010; 363: 609-619.

17. Evans M, Tettamanti G, Nyren O et al. No survival benefit from early-start dialysis in a population-based, inception cohort study of Swedish patients with chronic kidney disease. J Intern Med 2011; 269: 289-298.

18. Cooper BA, Branley P, Bulfone L et al. The Initiating Dialysis Early and Late (IDEAL) study: study rationale and design. Perit Dial Int 2004; 24: 176-181.

19. Rao PS, Schaubel DE, Jia X et al. Survival on dialysis post-kidney transplant failure: results from the Scientific Registry of Transplant Recipients. Am J Kidney Dis 2007; 49: 294-300.

20. Caldes Ruisanchez S, Marcen Letosa R, Amezquita Orjuela Y et al. Dialysis after kidney transplant failure: do patients start in a worse condition than the general population with chronic kidney disease? Nefrologia 2011; 31: 51-57.

21. de Jonge H, Bammens B, Lemahieu W et al. Comparison of peritoneal dialysis and haemodialysis after renal transplant failure. Nephrol Dial Transplant 2006; 21: 1669-1674.

22. Badve SV, Hawley CM, McDonald SP et al. Effect of previously failed kidney transplantation on peritoneal dialysis outcomes in the Australian and New Zealand patient populations. Nephrol Dial Transplant 2006; 21: 776-783.

23. Mujais S, Story K. Patient and technique survival on peritoneal dialysis in patients with failed renal allograft: a case-control study. Kidney Int Suppl 2006S133-S137.

24. Duman S, Asci G, Toz H et al. Patients with failed renal transplant may be suitable for peritoneal dialysis. Int Urol Nephrol 2004; 36: 249-252.

25. Sasal J, Naimark D, Klassen J et al. Late renal transplant failure: an adverse prognostic factor at initiation of peritoneal dialysis. Perit Dial Int 2001; 21: 405-410.

26. Davies SJ. Peritoneal dialysis in the patient with a failing renal allograft. Perit Dial Int 2001; 21Suppl 3S280-S284.

27. US Renal Data SystemUSRDS 2010 Annual Data Report: Atlas of Chronic Kidney Disease and End-Stage Renal Disease in the United States 2010Bethesda, MDNational Institutes of Health, National Institute of Diabetes and Digestive and Kidney Diseases

28. US renal Data SystemUSRDS 2009 Annual Data Report: Atlas of Chronic Kidney Disease and End Stage Renal Disease in the United States 2007Bethesda, MDNational Institutes of Health, National Institute of Diabetes and Digestive and Kidney Diseases

29. Gill JS, Abichandani R, Kausz AT et al. Mortality after kidney transplant failure: the impact of non-immunologic factors. Kidney Int 2002; 62: $1875-1883$.
30. Joffe MM, Rosenbaum PR. Invited commentary: propensity scores. Am J Epidemiol 1999; 150: 327-333.

31. D'Agostino RB, Jr. Propensity score methods for bias reduction in the comparison of a treatment to a non-randomized control group. Stat Med 1998; 17: 2265-2281.

32. Durrleman S, Simon R. Flexible regression models with cubic splines. Stat Med 1989; 8: 551-561.

33. Liberek T, Warzocha A, Galgowska $\mathrm{J}$ et al. When to initiate dialysis -is early start always better?. Nephrol Dial Transplant 2011; 26: 2087-2091

34. Bonomini V, Albertazzi A, Vangelista A et al. Residual renal function and effective rehabilitation in chronic dialysis. Nephron 1976; 16: 89-102.

35. Bonomini V, Feletti C, Scolari MP et al. Benefits of early initiation of dialysis. Kidney Int Suppl 1985; 17: S57-S59.

36. Bonomini V, Vangelista A, Stefoni S. Early dialysis in renal substitutive programs. Kidney Int Suppl 1978S112-S116.

37. Ratcliffe PJ, Phillips RE, Oliver DO. Late referral for maintenance dialysis. BMJ 1984; 288: 441-443.

38. Jungers P, Zingraff J, Albouze G et al. Late referral to maintenance dialysis: detrimental consequences. Nephrol Dial Transplant 1993; 8: 1089-1093.

39. Tattersall J, Greenwood R, Farrington K. Urea kinetics and when to commence dialysis. Am J Nephrol 1995; 15: 283-289.

40. Adequacy of dialysis and nutrition in continuous peritoneal dialysis: association with clinical outcomes. Canada-USA (CANUSA) Peritoneal Dialysis Study Group. J Am Soc Nephrol 1996; 7: 198-207.

41. Lindholm B, Davies S. End-stage renal disease in 2010: timing of dialysis initiation and choice of dialysis modality. Nat Rev Nephrol 2011; 7: 66-68

42. Faust J, Schreiner O. Early versus late initiation of dialysis. $N$ Engl $J$ Med 2010; 363: 2368-2369. author reply 2369-2370

43. Burton JO, Jefferies HJ, Selby NM et al. Hemodialysis-induced repetitive myocardial injury results in global and segmental reduction in systolic cardiac function. Clin J Am Soc Nephrol 2009; 4: 1925-1931.

44. Burton JO, Jefferies HJ, Selby NM et al. Hemodialysis-induced cardiac injury: determinants and associated outcomes. Clin $\mathrm{J} \mathrm{Am}$ Soc Nephrol 2009; 4: 914-920.

45. Bloembergen WE, Hakim RM, Stannard DC et al. Relationship of dialysis membrane and cause-specific mortality. Am J Kidney Dis 1999; 33: 1-10.

46. Chavers BM, Solid CA, Gilbertson DT et al. Infection-related hospitalization rates in pediatric versus adult patients with end-stage renal disease in the United States. J Am Soc Nephrol 2007; 18: 952-959.

47. Allon M, Depner TA, Radeva M et al. Impact of dialysis dose and membrane on infection-related hospitalization and death: results of the HEMO Study. J Am Soc Nephrol 2003; 14: 1863-1870.

48. Orofino L, Marcen R, Quereda C et al. Epidemiology of symptomatic hypotension in hemodialysis: is cool dialysate beneficial for all patients?. Am J Nephrol 1990; 10: 177-180.

49. Cukor D, Coplan J, Brown C et al. Depression and anxiety in urban hemodialysis patients. Clin J Am Soc Nephrol 2007; 2: 484-490.

50. Grootendorst DC, Michels WM, Richardson JD et al. The MDRD formula does not reflect GFR in ESRD patients. Nephrol Dial Transplant 2011; 26: 1932-1937.

51. Noori N, Kopple JD, Kovesdy CP et al. Mid-arm muscle circumference and quality of life and survival in maintenance hemodialysis patients. Clin J Am Soc Nephrol 2010; 5: 2258-2268.

52. Beddhu S, Samore MH, Roberts MS et al. Creatinine production, nutrition, and glomerular filtration rate estimation. J Am Soc Nephrol 2003; 14: 1000-1005.

53. Kalantar-Zadeh K, Streja E, Molnar MZ et al. Mortality prediction by surrogates of body composition: an examination of the 'obesity paradox' in hemodialysis patients using composite ranking score analysis. Am J Epidemiol 2012 
54. Molnar MZ, Streja E, Kovesdy CP et al. Associations of body mass index and weight loss with mortality in transplant-waitlisted maintenance hemodialysis patients. Am J Transplant 2011; 11: $725-736$.

55. Kalantar-Zadeh K, Streja E, Kovesdy CP et al. The obesity paradox and mortality associated with surrogates of body size and muscle mass in patients receiving hemodialysis. Mayo Clin proc 2010; 85 : 991-1001.

56. Noori N, Kovesdy CP, Bross R et al. Novel equations to estimate lean body mass in maintenance hemodialysis patients. Am J Kidney Dis 2011; 57: 130-139.

Received for publication: 26.8.2011; Accepted in revised form: 2.1.2012

\title{
Depressive symptoms associate with high mortality risk and dialysis withdrawal in incident hemodialysis patients
}

\author{
Eduardo Lacson, $\mathrm{Jr}^{1}$, Nien-Chen $\mathrm{Li}^{1}$, Sandie Guerra-Dean ${ }^{1}$, Michael Lazarus ${ }^{1}$, Raymond Hakim ${ }^{1}$ \\ and Fredric O. Finkelstein ${ }^{2}$ \\ ${ }^{1}$ Fresenius Medical Care North America, Waltham, MA, USA and ${ }^{2}$ Hospital of St. Raphael and Yale University, New Haven, CT, \\ USA \\ Correspondence and offprint requests to: Eduardo Lacson; E-mail: elacsonj@fmc-na.com
}

\begin{abstract}
Background. The relationship between severity of depressive symptoms reported by incident dialysis patients and first-year outcomes is not known.

Methods. We evaluated the association between selfreport of depressive symptoms in incident hemodialysis patients admitted at Fresenius Medical Care North America facilities between 1 January and 31 December 2006 and mortality or withdrawal from dialysis for up to 1 year after the initial survey. The impact of depression scores calculated from two Short Form-36 (SF-36) questionnaires was determined independently of the mental and physical component scores, casemix and laboratory variables using stepwise Cox models.

Results. We received 6415 SF-36 responses within 46 \pm 24 days of first dialysis from a cohort with a mean age of $62.3 \pm 15.2$ years; $58 \%$ were diabetic, $45 \%$ were female and $69 \%$ were Caucasian. A 1-point increase in depression score was associated with unadjusted hazard ratio $(\mathrm{HR})$ of $1.09(1.03,1.15)$ for mortality and $1.15(1.05,1.26)$ for withdrawal from dialysis. After adjustment, a 1-point increase in depression score had a mortality HR of $1.08(1.01,1.14)$ and for withdrawal 1.19 (1.08, 1.31).

Conclusions. Depressive symptoms reported within the first 90 days of dialysis were associated with greater dialysis withdrawal and mortality risk over the succeeding year. Whether further evaluation for and treatment of depression during this early vulnerable period may improve symptoms, increase survival and decrease premature withdrawal from dialysis requires confirmation in prospective clinical trials.
\end{abstract}

Keywords: chronic kidney disease; death; depression; ESRD; quality of life

\section{Introduction}

The impact of psychosocial factors, including depressive symptoms, on the outcomes of dialysis patients has been emphasized in several studies [1-15]. In the Dialysis Outcomes and Practice Patterns Study (DOPPS), the presence of depressive symptoms, as assessed by the Center for Epidemiologic Studies Depression Scale (CES-D) or by the two depression questions on the Medical Outcomes Study Short Form36 (SF-36), was strongly associated with mortality and hospitalizations in a large cohort of prevalent hemodialysis (HD) patients maintained on dialysis for a median time of $>2.4$ years [4].

High mortality rates during the first year of end-stage renal disease (ESRD) for patients maintained on HD has captured the renal community's attention [16]. While $25-30 \%$ of prevalent ESRD patients have clinical depression [8], Watnick et al. [17] observed that among 123 incident dialysis patients screened within 10 days of starting dialysis, $44 \%$ had Beck Depression Inventory (BDI) scores above the validated cutoff for clinical depression. Two recent studies have begun to focus their attention on the association of depressive symptoms and mortality in chronic kidney disease and incident ESRD patients [13, 14]. Although with small sample sizes, their findings suggest that depressive symptoms in the period prior to dialysis and shortly 